\title{
Studying the electrical, thermal, and photocatalytic activity of nanocomposite of polypyrrole with the photoadduct of $\mathrm{K}_{3}\left[\mathrm{Fe}(\mathrm{CN})_{6}\right]$ and diethylenetriamine
}

\author{
Syed Kazim Moosvia, Kowsar Majid ${ }^{a *}$, Tabassum Ara ${ }^{a}$ \\ ${ }^{a}$ Department of Chemistry, National Institute of Technology Srinagar-190 006, J \& K, India
}

Received: December 24, 2015; Revised: May 10, 2016; Accepted: June 18, 2016

\begin{abstract}
The present work reports the synthesis of nanocomposite of polypyrrole with $\left[\mathrm{Fe}(\mathrm{CN})_{3}(\operatorname{dien})\right] \cdot \mathrm{H}_{2} \mathrm{O}$ photoadduct via in-situ oxidative chemical polymerisation. Photoadduct was synthesised by irradiating an equimolar mixture of $\mathrm{K}_{3}\left[\mathrm{Fe}(\mathrm{CN})_{6}\right]$ and diethylenetriamine (dien) using Osram photo lamp. The successful synthesis of photoadduct was proved by Elemental analysis, UV-Vis and FTIR spectra. Nanocomposite of photoadduct with PPY was then prepared by oxidative chemical polymerization using $\mathrm{FeCl}_{3}$ as oxidant. The successful synthesis of the nanocomposite was confirmed from FTIR, XRD and SEM. The nanocomposite showed significant increase in thermal stability, dielectric constant and ac-conductivity as compared to pure polypyrrole. The photocatalytic activity of the materials was also studied against the methyl orange (MO) dye under UV-Vis light and nanocomposite showed efficient photocatalytic activity ( $91 \%$ degradation after $2 \mathrm{hrs)} \mathrm{than} \mathrm{pure} \mathrm{PPY} \mathrm{which} \mathrm{showed} \mathrm{only} 24 \%$ degradation of dye after $2 \mathrm{hrs}$. Thus as synthesised nanocomposite can be effectively utilised for the removal of organic dyes.
\end{abstract} $s t u d y$.

\section{Introduction}

Conducting polymers have attracted a considerable attention from all polymer branches owing to their interesting technological applications such as energy storage devices, sensors, and strong EMI materials ${ }^{1}$. However to make them technologically more viable, tuning of various physical and chemical properties is essential. For this purpose many conducting polymer/ inorganic composites have been made which show improved properties compared with those of pure conducting polymers or inorganic materials ${ }^{2}$. The creation of polymer/ inorganic nanocomposites has attracted intensive research owing to their unique physical properties ${ }^{3}$. Properties such as environmental stability, processibility, mechanical properties, solubility for processing and thermal stability can be enhanced by forming a polymer nanocomposite ${ }^{4}$. Conducting polymer nanocomposites find applications in batteries, molecular electronics, conducting paints and photovoltaic cells $\mathrm{s}^{5}$.

Among organic conducting polymers, polypyrrole (PPY) is of special interest because of its easy preparation and unique properties such as excellent environmental stability and potential application in electronic devices ${ }^{6,7}$. Composites composed of PPY with nanoparticles are currently of great research interest. In this direction, various composites of PPY have been synthesized with various organic, inorganic metal oxides, SWCNT, MWCNT, nanoparticles by

* e-mail: kowsarmajid@rediffmail.com chemical or electrochemical route ${ }^{8}$. For instance PPY/ $\mathrm{TiO}_{2}$ nanocomposite exhibit photocatalytic activity ${ }^{9}$, nanocomposite of polypyrrole with silicon has been reported to show Li storage properties ${ }^{10}$, PPY/CNT nanocomposite as electrode for supercapacitor ${ }^{11}$, nanocomposite of PPY with nanoparticle has been reported to show enhanced thermal stability, dielectric constant and ac- conductivity ${ }^{12}$ etc. The aim of this paper is to synthesise a nanocomposite of polypyrrole with nanophotoadduct of photoactive transition metal complex viz. potassium hexacyanoferrate(III) and diethylenetriamine (dien) ligand. Since nanophotoadduct contains both organic and inorganic ligands, can prove as potent filler and is expected to be able to make various augmentations in nanocomposite properties such as electrical, thermal and photocatalytic properties. SEM, XRD and FTIR spectra were used here to investigate the morphology and structure of the products.

\section{Experimental}

\subsection{Chemicals}

Materials used in this work were pyrrole (Himedia), potassium ferricyanide, anhydrous ferric chloride and diethylenetriamine (dien) all supplied by Loba chemicals. Pyrrole monomer was purified by simple distillation. All the chemicals used in the experimental work were of analytical grade. Distilled deionised water was used throughout this work. 


\subsection{Physical measurements}

UV-Vis absorption spectrum was obtained on double beam spectrophotometer (PG instruments T80). FTIR analysis was done by using Perkin Elmer RX-1, FTIR spectrophotometer by mixing the powder with dry $\mathrm{KBr}$. Irradiation was done with Osram UV photolamp. SEM analysis was carried out by using Hitachi FE-SEM, Model $\mathrm{S}-3600 \mathrm{~N}$. XRD pattern was obtained on PW 3050 base diffractometer, operating with $\mathrm{Cu}-\mathrm{K} \alpha$ radiations $(\lambda=$ $1.54060 \AA)$. Dielectric study was carried out using Agilent 4285 A precision LCR meter at room temperature in the frequency range of $20 \mathrm{~Hz}-1 \mathrm{MHz}$. For this purpose the powder was pressed into circular pellets of diameter $10 \mathrm{~mm}$ and thickness $2.35 \mathrm{~mm}$. Silver paint was applied on both sides of the pellet and air dried to have good ohmic contact.

\subsection{Synthesis of nanophotoadduct}

The photoadduct of $\mathrm{K}_{3}\left[\mathrm{Fe}(\mathrm{CN})_{6}\right]$ and diethylenetriamine (dien) was synthesised by irradiating an equimolar mixture of $\mathrm{K}_{3}\left[\mathrm{Fe}(\mathrm{CN})_{6}\right]$ and dien in water for half an hour using Osram photolamp. The mixture was irradiated till the color changed from yellow to dark brown. This process was carried out in dark. The mixture was concentrated on water bath and cooled to room temperature. The product obtained was then recrystallized for purification and was subjected to various spectroscopic and surface characterizations. The reduction of photoadduct to nanosize was done by ball milling using 30 zirconium balls of $5 \mathrm{~mm}$ size for $10 \mathrm{hrs}$ at $450 \mathrm{rpm}$. The reduction of photoadduct to nanosize was confirmed from XRD.

\subsection{Synthesise of PPY/ nanophotoadduct composite}

Chemical method was used for the preparation of nanocomposite of PPY with nanophotoadduct in non-aqueous medium (Chloroform). $\mathrm{FeCl}_{3}$ was used as an oxidising agent. In a typical experiment, 0.055 $\mathrm{mol} \mathrm{FeCl}_{3}$ in $180 \mathrm{ml}$ of chloroform was added to the stirred solution of $0.022 \mathrm{~mol}$ (in $70 \mathrm{ml}$ chloroform) of distilled pyrrole monomer drop wise. To this mixture $1 \mathrm{~g}$ of nanophotoadduct was then added for nanocomposite formation. The mixture was kept stirring for 24 hours. After 24 hours product was filtered and was then washed several times with methanol in order to remove oligomers and impurities. The black powder was then dried at room temperature.

\subsection{Photocatalytic activity}

The photocatalytic efficiency of the PPY and its nanocomposite was studied for degradation of methyl orange (MO) dye in presence of UV-Vis light using Mercury-Xenon arc lamp with the range of wavelength from $250-580 \mathrm{~nm}$. The power of the lamp used was 470 watts. $0.4 \mathrm{~g}$ of PPY and nanocomposite was suspended into the $50 \mathrm{ppm}$ aqueous solution of MO $(200 \mathrm{ml})$. Prior to irradiation the suspension was stirred for some time in dark so as to attain adsorption - desorption equilibrium. Then the suspension was irradiated under Mercury-Xenon arc lamp. During irradiation stirring was maintained to keep the mixture in suspension. At the given time intervals $5 \mathrm{ml}$ of sample were collected from the suspension and analysed by a UV-Vis double beam spectrophotometer (PG instruments T80). The absorbance of $\mathrm{MO}$ solution was recorded at a wave length of $500 \mathrm{~nm}$.

\section{Results and discussions:}

\subsection{UV-Visible characterization:}

The UV-Vis spectra of an aqueous solution mixture of $\mathrm{K}_{3}\left[\mathrm{Fe}(\mathrm{CN})_{6}\right]$ and diethylenetriamine shows two peaks at $230 \mathrm{~nm}$ and $417 \mathrm{~nm}$ before irradiation as shown in Figure 1(a). These peaks are assigned to charge transfer transitions ${ }^{13}$. After irradiation the spectra (Figure 1(b)) shows two peaks at $\lambda_{\text {max }}$ of $230 \mathrm{~nm}$ and $444 \mathrm{~nm}$. Thus a shift of peak from $417 \mathrm{~nm}$ to $445 \mathrm{~nm}$ has taken place which indicates some change in the energy levels of transition metal complex has taken place due to the incorporation of dien, hence indicates the successful photoirradiation and photosubstitution.

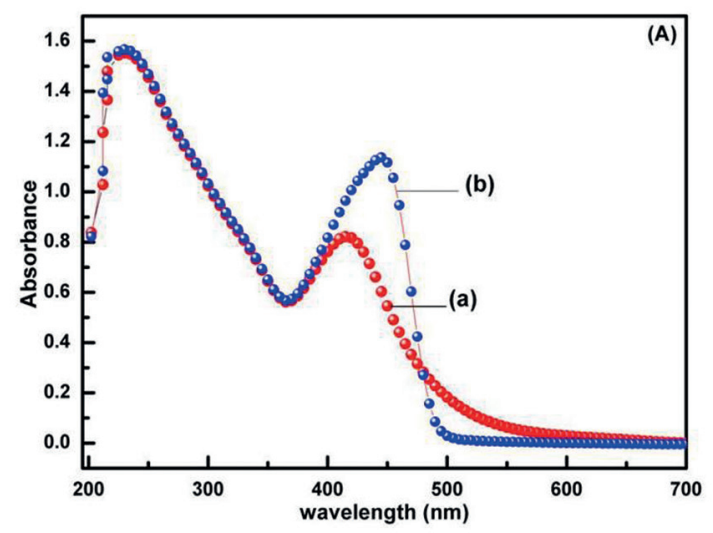

Figure 1: UV-Visible spectra of : aqueous solution of $\mathrm{K}_{3}\left[\mathrm{Fe}(\mathrm{CN})_{6}\right]$ and diethylenetriamine (dien) (a) before irradiation and (b) after irradiation.

\subsection{Elemental analysis:}

The complex formed between $\mathrm{K}_{3}\left[\mathrm{Fe}(\mathrm{CN})_{6}\right]$ and diethylenetriamine (dien) by photosubstitution process was analysed for $\mathrm{C}, \mathrm{H}$ and $\mathrm{N}$ and the empirical formula proposed for the complex was found to be 
$\left[\mathrm{Fe}(\mathrm{CN})_{3}(\right.$ dien $\left.)\right] \cdot \mathrm{H}_{2} \mathrm{O}$. The observed percentage of $\mathrm{C}$, $\mathrm{N}$, and $\mathrm{H}$ are $32.79 \%, 32.83 \%$ and $5.65 \%$, respectively, against the calculated percentages $\mathrm{C}=32.58 \%, \mathrm{~N}$ $=32.58 \%$, and $\mathrm{H}=5.82 \%$.

\subsection{FTIR Characterization}

FTIR spectra of $\mathrm{K}_{3}\left[\mathrm{Fe}(\mathrm{CN})_{6}\right]$, nanophotoadduct, PPY and nanocomposite are shown in Figure 2 (a-d). FTIR of $\mathrm{K}_{3}\left[\mathrm{Fe}(\mathrm{CN})_{6}\right]$ as shown in Figure 2(a) exhibit peaks at $\left(3464 \mathrm{~cm}^{-1}, 1630 \mathrm{~cm}^{-1}\right),(2118,2076,2043)$ $\mathrm{cm}^{-1}$ and $511 \mathrm{~cm}^{-1}$ which are attributed to $v(\mathrm{OH})$ of lattice water (symmetric and antisymmetric), $\delta(\mathrm{H}-\mathrm{O}-\mathrm{H})$, $v(\mathrm{C} \equiv \mathrm{N})$ and $v(\mathrm{Fe}-\mathrm{CN})$ vibrational modes respectively ${ }^{14}$. The FTIR spectra of diethylenetriamine exhibits peaks at $3300 \mathrm{~cm}^{-1}, 3000 \mathrm{~cm}^{-1}, 1800 \mathrm{~cm}^{-1}, 1600 \mathrm{~cm}^{-1}, 1400$ $\mathrm{cm}^{-1}, 1200 \mathrm{~cm}^{-1}, 900 \mathrm{~cm}^{-1}$. These peaks are assigned to $\mathrm{NH}_{2}$ stretching vibration $\left(v-\mathrm{NH}_{2}\right), \mathrm{CH}_{2}$ stretching vibration $\left(v-\mathrm{CH}_{2}\right), \mathrm{NH}_{2}$ bending $\left(\delta-\mathrm{NH}_{2}\right), \tau-\mathrm{CH}_{2}, \mathrm{CH}_{2}$ bending $\left(\delta-\mathrm{CH}_{2}\right), \mathrm{CN}$ stretching vibration $(v-\mathrm{CN}) \&$ $\mathrm{NH}$ stretching vibration $(v-\mathrm{NH})$ respectively ${ }^{15}$.

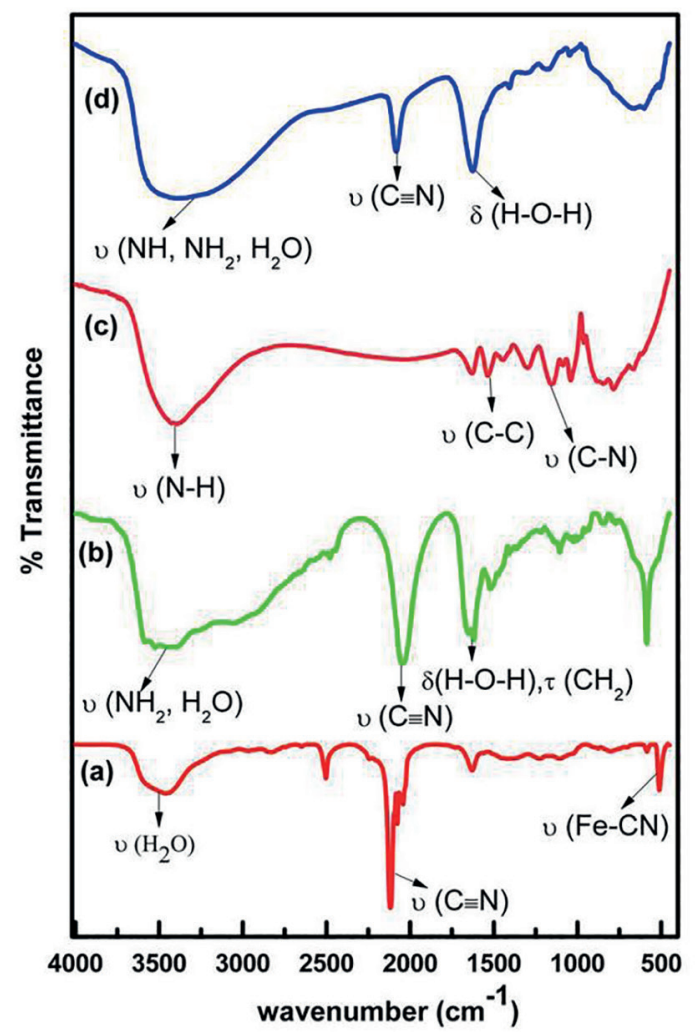

Figure 2: FTIR spectra of (a) $\mathrm{K}_{3}\left[\mathrm{Fe}(\mathrm{CN})_{6}\right]$, (b) nanophotoadduct, (c) Polypyrrole and (d) nanocomposite.

The FTIR spectra of photoadduct as shown in Figure 2 (b) shows a broad peak at $3500 \mathrm{~cm}^{-1}$ owing to $\left(\mathrm{NH}_{2}\right.$, $\mathrm{NH}$ and $\mathrm{CH}_{2}$ ) stretching vibrations. This peak is broad since $\mathrm{H}_{2} \mathrm{O}$ also gives a peak in the same the region assigned to its symmetric vibration. Presence of water is also confirmed from the absorption peak at 1620 $\mathrm{cm}^{-1}$. The presence of water outside the coordination sphere is also confirmed from thermal analysis, which shows a weight loss equivalent to one mole of water, observed at a temperature range of $28{ }^{\circ} \mathrm{C}$ to $103{ }^{\circ} \mathrm{C}$. Peaks at $2043 \mathrm{~cm}^{-1}$ due to $\mathrm{C} \equiv \mathrm{N}$ stretching, (1620, 1508) $\mathrm{cm}^{-1}$ due to $\left(\mathrm{NH}_{2}\right.$ bending, $\mathrm{CH}_{2}$ bending, $\mathrm{CH}_{2}$ wag, $\mathrm{NH}_{2}$ wag), $1211 \mathrm{~cm}^{-1}$ due to $\mathrm{CH}_{2}$ deformations $(1100,1000,757) \mathrm{cm}^{-1}$ due to skeletal stretching vibration of C-C, C-N, $587 \mathrm{~cm}^{-1}$ due to N-C-C-N and $\mathrm{N}-\mathrm{Fe}-\mathrm{N}$ bending vibration clearly indicate the presence of characteristic peaks of both $\mathrm{K}_{3}\left[\mathrm{Fe}(\mathrm{CN})_{6}\right]$ and dien, though with some shifts, thus proving the successful formation of photoadduct.

Figure 2(c) shows the FTIR spectra of PPY. Polypyrrole exhibit characteristic peaks at $3391 \mathrm{~cm}^{-1}$, $1536 \mathrm{~cm}^{-1}, 1444 \mathrm{~cm}^{-1}, 1297 \mathrm{~cm}^{-1}, 1041 \mathrm{~cm}^{-1}, 784 \mathrm{~cm}^{-1}$ and $606 \mathrm{~cm}^{-1}$ which are attributed to $v(\mathrm{~N}-\mathrm{H}), v(\mathrm{C}-\mathrm{C})$, $v(\mathrm{C}=\mathrm{C}), v(\mathrm{C}-\mathrm{N}), \mathrm{C}-\mathrm{N}$ in plane deformation mode, $\mathrm{C}-\mathrm{H} \& \mathrm{~N}-\mathrm{H}$ in plane deformation vibration and $\mathrm{C}-\mathrm{H}$ outer bending vibrations respectively. The insertion of photoadduct in the PPY matrix is evident by the appearance of a peak at $2084 \mathrm{~cm}^{-1}$ (Figure 2(d)), which is due to $v(\mathrm{C} \equiv N)$. This peak appears at 2043 $\mathrm{cm}^{-1}$ in the nanophotoadduct with a strong intensity. This decrease in intensity and shifting of absorption peak by $41 \mathrm{~cm}^{-1}$ indicates the successful insertion of nanophotoadduct in the polypyrrole matrix. Further the insertion of photoadduct in PPY is also evident by appearance of absorption peaks due to dien with some shifts. Such peak shifting is mainly attributed to the interaction between PPY and photoadduct. This interaction may cause high efficiency of charge separation and prompt synergistic effect to enhance the photocatalytic efficiency of PPY.

Thus from the discussion of FTIR spectra of $\mathrm{K}_{3}\left[\mathrm{Fe}(\mathrm{CN})_{6}\right]$, nanophotoadduct, pure PPY and the nanocomposite of PPY with synthesised nanophotoadduct, the successful formation of photoadduct and its nanocomposite is evident.

\section{4. $X R D$}

The XRD data has been analysed using powder $\mathrm{X}$ software. The XRD diffraction pattern of PPY, nanophotoadduct and nanocomposite is shown in Figure 3 (a-c) respectively. PPY shows a hump at 2 theta value of $30^{\circ}$ which indicates its amorphous nature ${ }^{16}$. The appearance of sharp peaks in the XRD of nanophotoadduct shows crystalline nature of nanophotoadduct. The XRD pattern of nanocomposite confirms the insertion of photoadduct in the polymer matrix. The lattice parameters $(\mathrm{a}=$ 13.96996, $b=10.38228, c=8.30547, \alpha=\gamma=89.8, \beta$ 


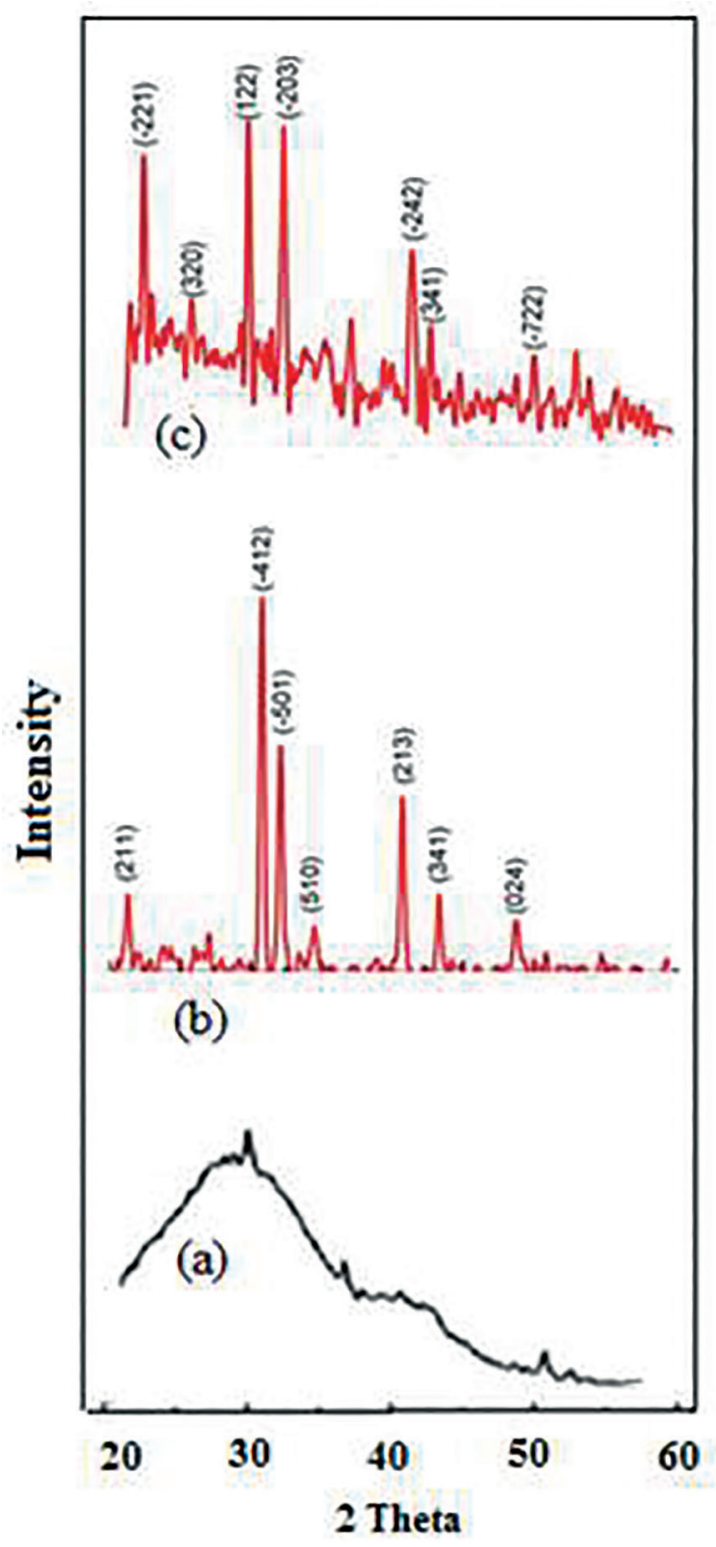

Figure 3: XRD of (a) PPY (b) nanophotoadduct (c) nanocomposite.

$=106.3$ ) obtained after refinement shows monoclinic structure of nanophotoadduct. The lattice parameters obtained for nanocomposite after refinement are $\mathrm{a}=$ 13.96298, $b=10.36719, c=8.339, \alpha=\gamma=89.5$ and $\beta=$ 106.5). Thus the monoclinic structure of photoadduct is retained in the nanocomposite. The value of calculated $d$ spacing is in agreement with the experimental $d$ spacing as shown in table 1.1 and 1.2 respectively. The average crystallite size of nanophotoadduct and nanocomposite was calculated using Scherrer formula;

$$
\mathrm{D}=\mathrm{K} \lambda / \beta \cos \theta
$$

Where $\mathrm{D}$ is crystallite size, $\mathrm{K}=$ shape factor $(0.89)$ and $\lambda=$ wavelength of $\mathrm{Cu} \mathrm{k}_{\alpha}$ radiation $\left(1.54 \mathrm{~A}^{\circ}\right), \beta$ is full width at half maximum and $\theta$ is the Bragg angle. The average crystallite size of the nanophotoadduct and nanocomposite comes out to be $20 \mathrm{~nm}$ and 19 $\mathrm{nm}$ respectively.

\subsection{SEM characterization}

Figure 4(a-c) shows the SEM micrographs of nanophotoadduct, PPY and its nanocomposite respectively. SEM micrograph of photoadduct shows flat like crystals of irregular shapes. SEM micrograph of pure PPY shows grooves and spongy nature. However, the SEM of composite exhibits compact nature due to encapsulation of photoadduct within the matrix. This shows the successful formation of composite.

\subsection{Thermal analysis}

TGA of PPY shows two transitions as shown in Figure 5 (a). The first one which starts soon after ambient temperature with a weight loss of $3 \%$ may be attributed to the loss of embedded moisture. The second transition starts from $250{ }^{\circ} \mathrm{C}$ and ends at $580{ }^{\circ} \mathrm{C}$ with a weight loss of $100 \%$ and is due to the degradation of whole polymer chain ${ }^{17}$. The TG curve of photoadduct shows three transitions as shown in Figure 5(b). The first transition from $28{ }^{\circ} \mathrm{C}$ to $103{ }^{\circ} \mathrm{C}$ with a weight loss of $6.9 \%$ corresponds to the loss of one mole of water and is in accordance with the calculated weight loss of 7\%. The second transition starts from 103 ${ }^{\circ} \mathrm{C}$ and ends at $258{ }^{\circ} \mathrm{C}$ with a weight loss of $19.5 \%$ may be due to the loss of $\mathrm{N}_{2} \mathrm{H}_{4}$ and $\mathrm{NH}_{3}$, released by the degradation of dien ligand. This transition is in accordance with the calculated weight loss of $19.2 \%$. The third transition starts from $547^{\circ} \mathrm{C}$ and ends at 853 ${ }^{\circ} \mathrm{C}$. This transition corresponds to the weight loss of $52.5 \%$ and may be due to the loss of three molecules of $\mathrm{HCN}$ and two $\mathrm{C}_{2} \mathrm{H}_{2}$ moieties. This is in accordance with the calculated weight loss of $52.1 \%$. The rest is the residue left. The thermogram of nanocomposite shows three main transitions as shown in Figure 5 (c). The first transition from ambient to $62^{\circ} \mathrm{C}$ with a weight loss of $8 \%$ can be attributed to the loss of moisture. The second transition starts from $62{ }^{\circ} \mathrm{C}$ and ends at 260 ${ }^{\circ} \mathrm{C}$ with a weight loss of about $26 \%$ and may be due to the loss of ligand moiety form photoadduct. Then thermogram runs parallel up to $537^{\circ} \mathrm{C}$ where from a steep decomposition takes place till $838^{\circ} \mathrm{C}$ which may be due to the degradation of polymer chain and then it again runs parallel. From these results it is clear that the thermal stability of nanocomposite has significantly increased as compared to pure PPY. This confirms that the presence of photoadduct is responsible for the high thermal stability of nanocomposite in comparison with pure PPY. 
Table 1.1: Parameters evaluated from XRD of nanophotoadduct of potassium hexacyanoferrate(III) with diethylenetriamine.

\begin{tabular}{lllllc}
\hline $\mathrm{h}$ & $\mathrm{k}$ & 1 & Theta(obs) & $\mathrm{d}(\exp )$ & $\mathrm{d}(\mathrm{cal})$ \\
\hline 2 & 1 & 1 & 10.66325 & 4.16296 & 4.16556 \\
-4 & 1 & 2 & 15.39768 & 2.90113 & 2.90212 \\
-5 & 0 & 1 & 16.05299 & 2.78563 & 2.78866 \\
5 & 1 & 0 & 17.24349 & 2.59856 & 2.59543 \\
2 & 1 & 3 & 20.34392 & 2.21570 & 2.21527 \\
3 & 4 & 1 & 21.64334 & 2.08851 & 2.08792 \\
0 & 2 & 4 & 24.36121 & 1.86745 & 1.86795 \\
\hline
\end{tabular}

Table 1.2: Parameters evaluated from XRD data of nanocomposite of PPY with nanophotoadduct of potassium hexacyanoferrate(III) with diethylenetriamine.

\begin{tabular}{cccccc}
\hline $\mathrm{h}$ & $\mathrm{k}$ & 1 & Theta(exp) & $\mathrm{d}(\exp )$ & $\mathrm{d}(\mathrm{cal})$ \\
\hline-2 & 2 & 1 & 11.33226 & 3.92847 & 3.92643 \\
3 & 2 & 0 & 13.00917 & 3.42192 & 3.42347 \\
1 & 2 & 2 & 15.00638 & 2.97497 & 2.97678 \\
-2 & 0 & 3 & 16.23697 & 2.75490 & 2.75885 \\
-2 & 4 & 2 & 20.72989 & 2.17622 & 2.17724 \\
3 & 4 & 1 & 21.38762 & 2.11229 & 2.11218 \\
-7 & 2 & 2 & 25.02207 & 1.82118 & 1.82121 \\
\hline
\end{tabular}

\subsection{Electrical Studies}

$\mathrm{I}-\mathrm{V}$ characteristics of PPY and its nanocomposite recorded at room temperature are found to show ohmic behaviour as shown in Figure $6(\mathrm{a} \& \mathrm{~b})$. From the I-Vcurves of PPY and its nanocomposite the values of dc electrical conductivity $(\sigma)$ have been calculated by using the following relation ${ }^{18}$.

$$
\sigma=[(\mathrm{IxL}) /(\mathrm{VxA})]
$$

where $\mathrm{I}$ is the current, $\mathrm{V}$ is the voltage, $\mathrm{L}$ is the thickness and $\mathrm{A}$ is the cross-section area of sample. The dc conductivity at room temperature in case of PPY and its nanocomposite comes out to be $5.38 \times 10^{-7} \mathrm{~S} \mathrm{~cm}^{-1}$ and $4 \times 10^{-6} \mathrm{~S} \mathrm{~cm}^{-1}$ respectively. Thus nanocomposite shows enhanced conductivity in comparison to PPY which can be attributed to the compactness and ordered structure of nanocomposite as is also evident from SEM and XRD.

\subsection{Dielectric study:}

Dielectric response of synthesised nanocomposite of PPY has been carried out by Agilent 4285A precision LCR meter as a function of frequency in the range of $20 \mathrm{~Hz}-1 \mathrm{MHz}$. Figure 7 (a-d) shows variation of $\varepsilon^{\prime}, \varepsilon^{\prime \prime}$, dielectric loss $(\tan \delta)$, and ac conductivity $\left(\sigma_{\mathrm{ac}}\right)$ with the frequency of applied electric field. The parameters have been calculated by using following relations:

$$
\begin{aligned}
& \varepsilon^{\prime}=\mathrm{C}_{\mathrm{p}} \mathrm{d} / \stackrel{\circ}{\varepsilon} \mathrm{A} \\
& \varepsilon^{\prime \prime}=\varepsilon^{\prime} \tan \delta \\
& \sigma_{\mathrm{ac}}=2 \pi v \varepsilon^{\prime \prime}
\end{aligned}
$$

where $\mathrm{C}_{\mathrm{p}}$ is the capacitance, $\mathrm{d}$ is the thickness of sample, $\varepsilon^{\circ}$ is the permittivity of the free space $\left(\varepsilon^{\circ}=8.854\right.$ $\times 10^{-12} \mathrm{~F} / \mathrm{m}$ ), and $\mathrm{A}$ is the effective area.

Figure $7(\mathrm{a} \& \mathrm{~b})$ depicts the frequency dependence of both real and imaginary part of dielectric constant. It is observed that dielectric constant decreases with increase in frequency. The decrease in dielectric constant is sharp initially from $20 \mathrm{~Hz}$ to $10^{3} \mathrm{~Hz}$ and then decreases slowly with increase in frequency and shows almost frequency independent behaviour at higher frequency region. The variation of dielectric constant with frequency may be explained on the bases of space charge polarization phenomenon ${ }^{19}$. At higher frequencies the value of dielectric constant remains almost constant; this is natural as the polarization of the induced moment could not synchronize the applied electric field at higher frequencies.

Variation of $\tan \delta$ with frequency is shown in Figure 7. (c). It is observed that the $\tan \delta$ shows a decreasing trend with increase in frequency. It is evident from the graph that the loss decreases rapidly in low frequency region and slowly in the higher frequency region. The low loss values at higher frequencies $\left(0.85\right.$ at $\left.10^{6} \mathrm{~Hz}\right)$ show the potential applications of nanocomposite in high frequency microwave devices.

Figure 7 (d) shows the variation of ac - conductivity at room temperature with frequency in the range of $20 \mathrm{~Hz}$ to $1 \mathrm{MHz}$. The ac - conductivity increases with increase in frequency. The frequency dependent behaviour can be explained on the bases of interface charge polarisation (Max-well Wagner-Sillars effect) ${ }^{20}$. This phenomenon occurs in heterogeneous systems like 

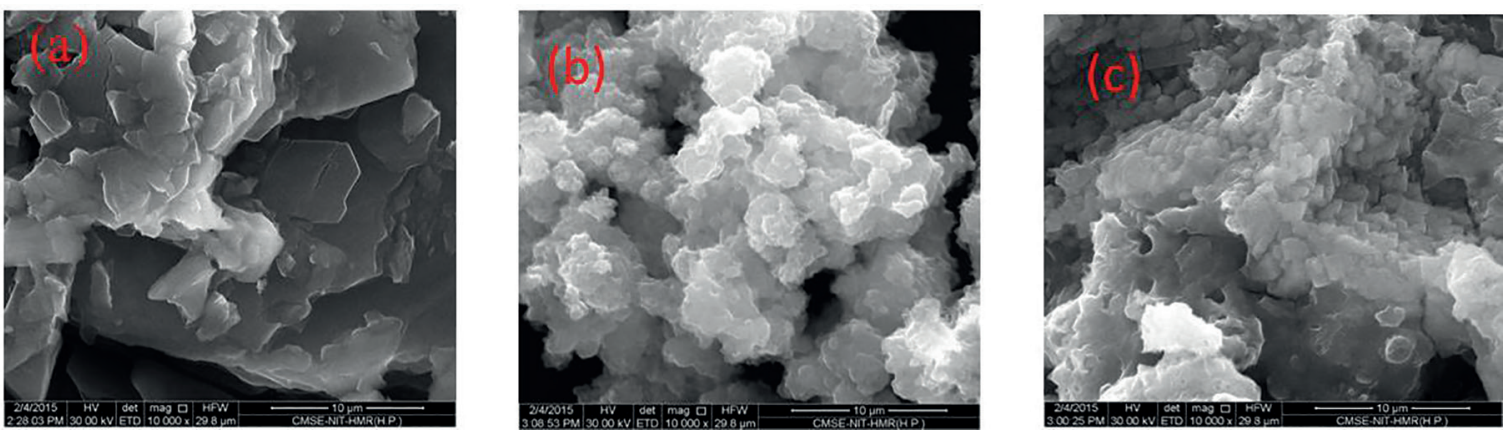

Figure 4: SEM micrographs of (a) nanophotoadduct (b) PPY (c) nanocomposite.

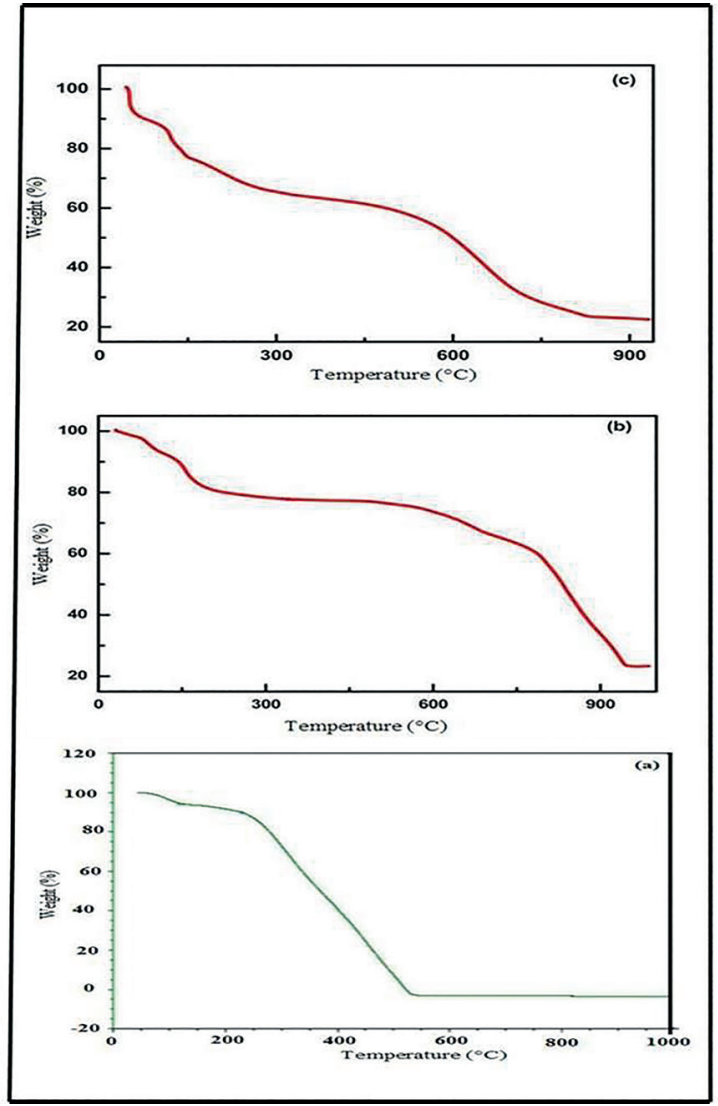

Figure 5: TGA of (a) PPY (b) nanophotoadduct (c) nanocomposite.

metal-polymer composites due to the accumulation of charges carriers at the interfaces. T.K Vishnuardhan et al have reported that the ac - conductivity of pure PPY is $1.26 \times 10^{-4} \mathrm{~S} / \mathrm{cm}$ at $10^{5} \mathrm{~Hz}^{21}$. Nanocomposite shows higher ac-conductivity $\left(2.46 \times 10^{8} \mathrm{~S} / \mathrm{m}\right.$ at the same frequency) than pure polymer. The improvement of ac-conductivity for nanocomposite comes from the effective dispersion of nanophotoadduct in the PPY matrix (shown in SEM images), which might encourage the formation of a more efficient network for charge transport in the polypyrrole matrix, resulting in higher conductivities.

\subsection{Photocatalytic activity}

In order to investigate the photocatalytic activity of nanocomposite, the photodegradation experiment of MO dye under UV-Vis light was carried out.

The percentage dye degradation was calculated using the formula

$$
\% \text { Degradation }=\frac{\mathrm{C}_{0}-\mathrm{C}_{\mathrm{t}}}{\mathrm{C}_{0}} \times 100
$$

Prior to irradiation the suspension of catalyst and dye was stirred in dark for 50 minutes so as to attain adsorption-desorption equilibrium between the catalyst and the dye. Figure 8 (b) shows the adsorption of dye is quite rapid in the first 30 minutes and then rises slowly with increase in adsorption time which indicates the attainment of adsorption-desorption equilibrium. It is clear from the Figure 8 (b) that the concentration of $\mathrm{MO}$ dye decreases with the irradiation time. The photocatalytic efficiency of nanocomposite is $91 \%$ in $2 \mathrm{hrs}$ irradiation time which is far higher than pure PPY (Figure 8 (a)) which shows only $27 \%$ in $2 \mathrm{hrs}$ irradiation time. The enhancement in dye degradation can be attributed to the synergistic interaction between PPY and nanophotoadduct which improves the charge transfer due to increased surface area of nanocomposite. The photocatalytic activity begins with the generation of electron hole pairs in the catalyst under UV-Vis light. These photoelectrons and holes form powerful oxidising species like $\mathrm{O}_{2}{ }^{-}$, $\cdot \mathrm{OH}$, and $\mathrm{HO}_{2}{ }_{2}$ etc. by reacting with the adsorbed $\mathrm{O}_{2}, \mathrm{OH}^{-}$and $\mathrm{H}_{2} \mathrm{O}$. The radical species $\left(\mathrm{O}_{2}^{{ }^{-}},{ }^{\circ} \mathrm{OH}\right.$, and $\mathrm{HO}_{2}$ ) thus generated degrade the $\mathrm{MO}$ dye adsorbed on the catalyst surface into small molecules like $\mathrm{CO}_{2}$ and $\mathrm{H}_{2} \mathrm{O}^{22}$. Thus the reason for the enhanced photocatalytic activity of nanocomposite might be due to the increased charge separation and the generation of oxyradicals $\left(\mathrm{O}_{2}{ }^{-}, \cdot \mathrm{OH}\right.$ and $\left.\mathrm{HO}_{2}^{\circ}\right)$.

Kinetics of the photodegradation rates of dye was also calculated, the photodegradation rates fit a pseudo first-order kinetic model that is $\ln \left(\mathrm{C}_{0} / \mathrm{C}_{\mathrm{t}}\right)=\mathrm{K}_{\mathrm{obs}} \mathrm{t}$ where 

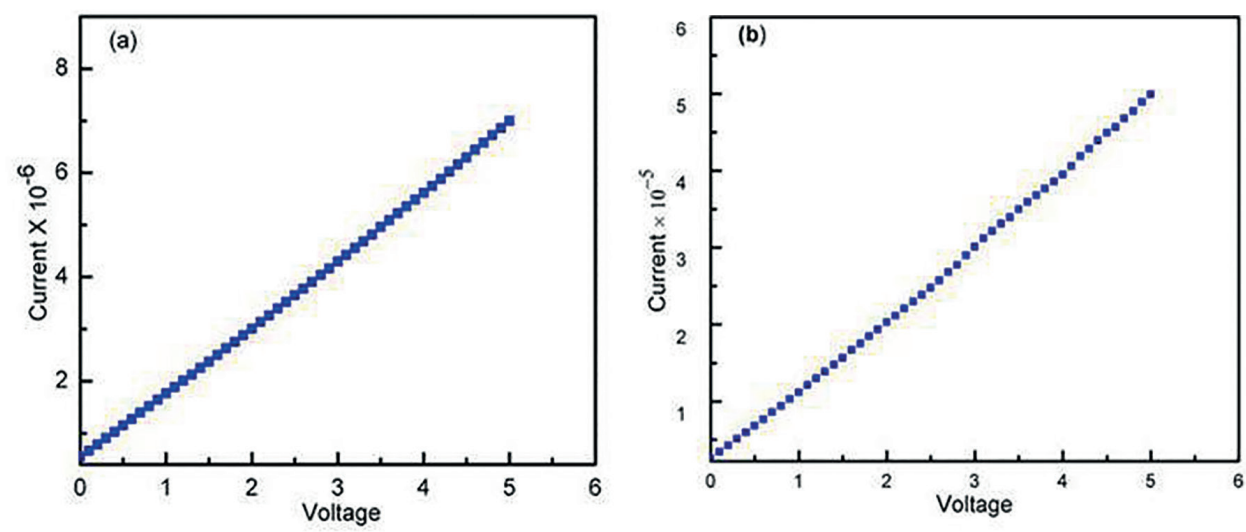

Figure 6: I-V characteristics of (a) PPY (b) nanocomposite.
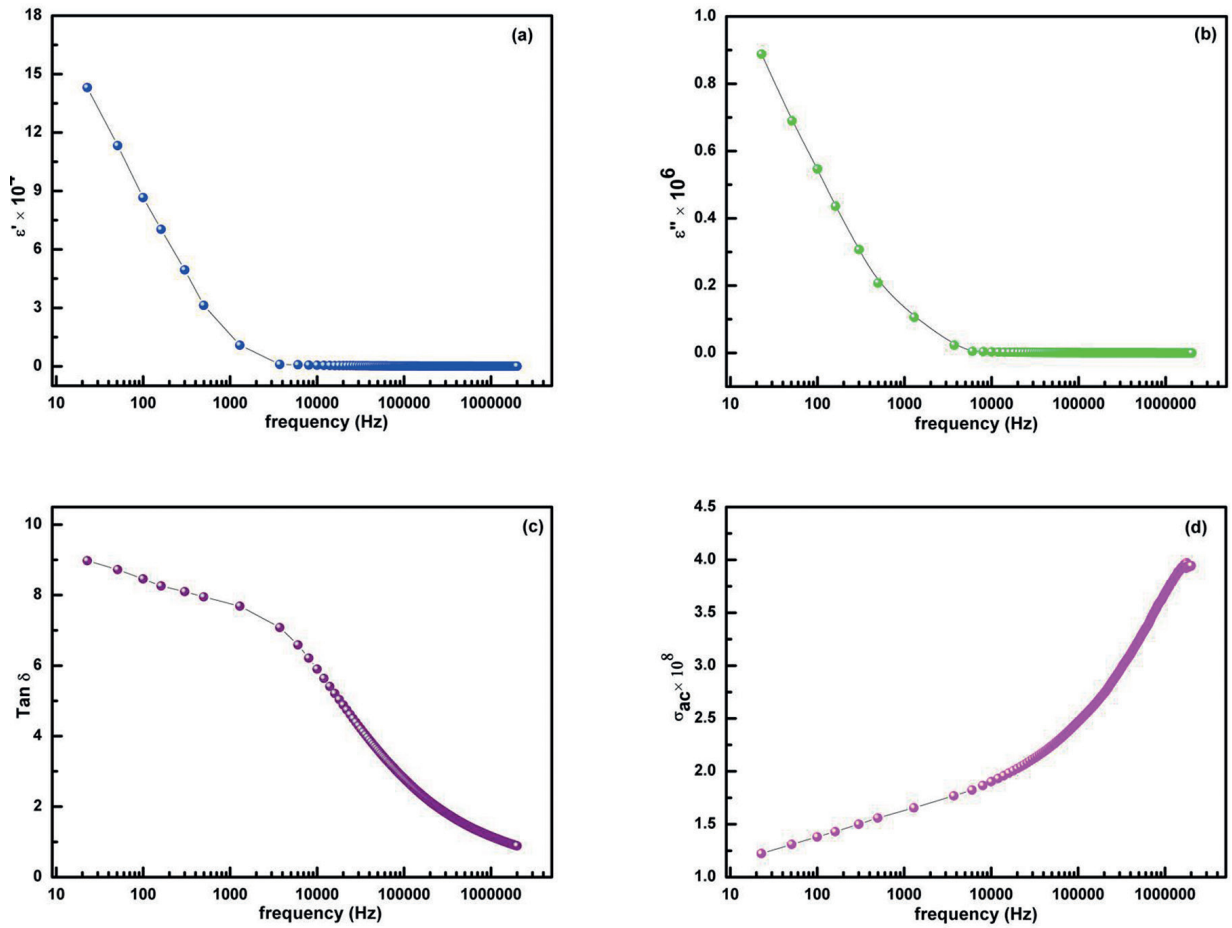

Figure 7: Variation of (a) real permittivity (b) imaginary permittivity (c) tangential loss (d) ac- conductivity with frequency.
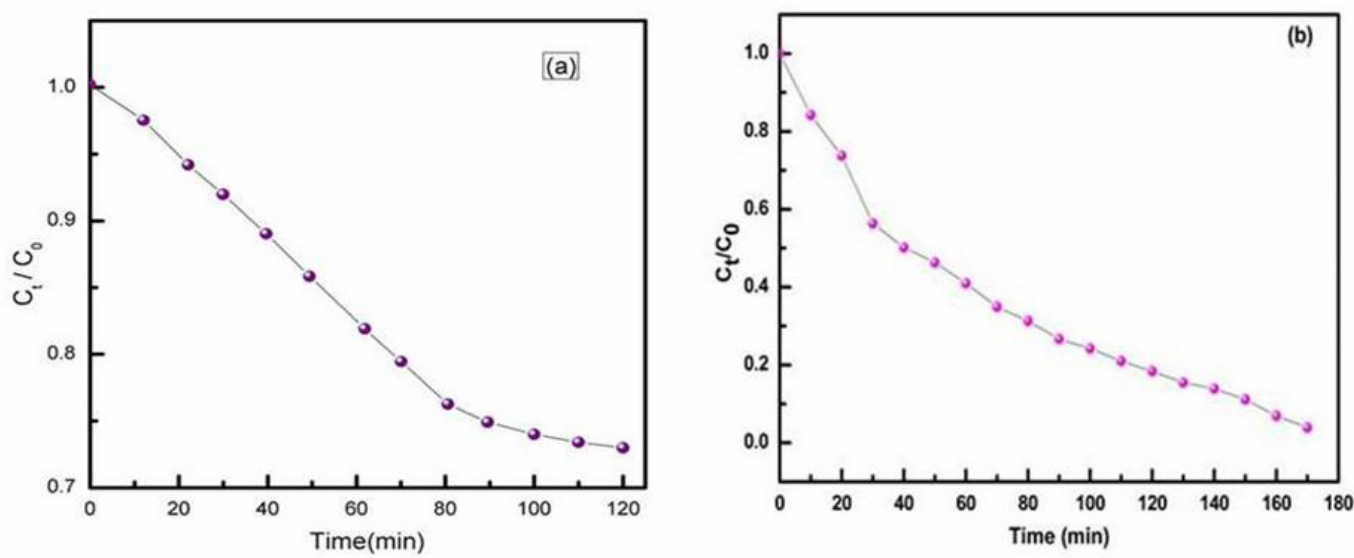

Figure 8: Plot of decrease in dye concentration $\mathrm{C}_{t} / \mathrm{C}_{0}$ with time in presence of (a) PPY (b) nanocomposite. 
$\mathrm{C}_{0}$ and $\mathrm{C}_{\mathrm{t}}$ are the concentration of $\mathrm{MO}$ dye at time 0 and $\mathrm{t}$, respectively. The $\mathrm{K}_{\text {obs }}$ is the observed pseudo first-order rate constant and $t$ is the reaction time. The value of $\mathrm{k}_{\mathrm{obs}}$ for nanocomposite is $7.62 \times 10^{-3}$ and for PPY is $2.4 \times 10^{-3}$ which clearly indicates the enhanced photocatalytic activity of nanocomposite as compared to PPY. Thus nanocomposite can be applied as an effective photocatalyst for the degradation of organic dye pollutants.

\section{Conclusion}

A nanocomposite of PPY and $\left[\mathrm{Fe}(\mathrm{CN})_{3}(\right.$ dien $\left.)\right] \cdot \mathrm{H}_{2} \mathrm{O}$ photoadduct was successfully synthesised which was confirmed from FTIR, XRD and SEM characterization techniques. The nanocomposite showed enhanced thermal stability \& electrical properties. The nanocomposite also exhibited good photocatalytic activity against MO dye degradation.

\section{Acknowledgement}

The authors are thankful to Prof Rajat Gupta, Director NIT Srinagar, for help and support.

\section{References}

1. John H, Thomas RM, Jacob J, Mathew KT, Joseph R. Conducting polyaniline composites as microwave absorbers. Polymer composites. 2007;28(5):588-592.

2. Mispa KJ, Subramaniam P, Murugesan R. Studies on ion-exchange properties of polyaniline $\mathrm{Zr}(\mathrm{IV})$ tungstoiodophosphate nanocomposite ion exchanger. Journal of Polymers. 2013;2013:356058.

3. Deivanayaki S, Ponnuswamy V, Mariappan R, Jayamurugan P. Synthesis and characterization of polypyrrole/ $\mathrm{TiO}_{2}$ composites by chemical oxidative method. Optik- International Journal for Light and Electron Optics. 2013;124(12):1089-1091.

4. Uygun A, Yavuz AG, Sen S, Omastová M. Polythiophene/ $/ \mathrm{SiO}_{2}$ nanocomposites prepared in the presence of surfactants and their application to glucose biosensing. Synthetic Metals. 2009;159(19-20):2022-2028.

5. Wang H, Lin T, Kaynak A. Polypyrrole nanoparticles and dye absorption properties. Synthetic Metals. 2005;151(2):136-140.

6. Wei S, Mavinakuli P, Wang Q, Chen D, Asapu R, Mao Y, et al. Polypyrrole-titania nanocomposites derived from different oxidants. Journal of the Electrochemical Society. 2011;158(11):K205-K212.

7. Lu X, Chao D, Chen J, Zhang W, Wei Y. Preparation and characterization of inorganic/organic hybrid nanocomposites based on Au nanoparticles and polypyrrole. Materials Letters. 2006;60(23):2851-2854.
8. Majid K, Tabassum R, Shah AF, Ahmad S, Singla ML. Comparative study of synthesis, characterization and electric properties of polypyrrole and polythiophene composites with tellurium oxide. Journal of Materials Science: Materials in Electronics. 2009;20(10):958-966.

9. Luo Q, Li X, Wang D, Wang Y, An J. Photocatalytic activity of polypyrrole/ $\mathrm{TiO}_{2}$ nanocomposites under visible and UV light. Journal of Materials Science. 2011;46(6):1646-1654.

10. Chew SY, Guo ZP, Wang JZ, Chen J, Munroe P, Ng SH, et al. Novel nano-silicon/polypyrrole composites for lithium storage. Electrochemistry Communications. 2007;9(5):941-946.

11. Lu X, Dou H, Yuan C, Yang S, Hao L, Zhang F, et al. Polypyrrole/ carbon nanotube nanocomposite enhanced the electrochemical capacitance of flexible graphene film for supercapacitors. Journal of Power Sources. 2012;197:319-324.

12. Varshney S, Singh K, Ohlan A, Jain VK, Dutta VP, Dhawan SK. Synthesis, characterization and surface properties of $\mathrm{Fe}_{2} \mathrm{O}_{3}$ decorated ferromagnetic polypyrrole nanocomposites. Journal of Alloys and Compounds. 2012;538:107-114.

13. Alexander JJ, Gray HB. Electronic structures of hexacyanometalate complexes. Journal of the American Chemical Society. 1968;90(16):4260-4271.

14. Nakagawa I, Shimanouchi T. Infrared spectroscopic study on the co-ordination bond-II: Infrared spectra of octahedral metal cyanide complexes. Spectrochimica Acta. 1962;18(1):101-113.

15. Yao W, Yu SH, Jiang J, Zhang L. Complex wurtzite ZnSe microspheres with high hierarchy and their optical properties. Chemistry (Weinheim an der Bergstrasse, Germany). 2006;12(7):2066-2072.

16. Upadhyay J, Kumar A. Investigation of structural, thermal and dielectric properties of polypyrrole nanotubes tailoring with silver nanoparticles. Composites Science and Technology. 2014;97:55-62.

17. Najar MH, Majid K. Nanocomposite of polypyrrole with the nanophotoadduct of sodium pentacyanonitrosylferrate(II) dihydrate and EDTA: A potential candidate for capacitor and a sensor for HF radio wave detection. Synthetic Metals. 2014;198:76-83.

18. Shaktawat V, Jain N, Saxena R, Saxena, NS, Sharma TP. Electrical conductivity and optical band gap studies of polypyrrole doped with different acids. Journal of Optoelectronics and Advanced Materials. 2007;9(7):2130-2132.

19. Farid MT, Ahmad I, Aman S, Kanwal M, Murtaza G, Ali I, et al. Structural, electrical and dielectric behaviour of $\mathrm{Ni}_{x} \mathrm{Co}_{1}-\mathrm{xNdyFe}_{2}-$ $\mathrm{yO}_{4}$ nano-ferrites synthesized by sol-gel method. Digest Journal of Nanomaterials and Biostructures. 2015;10(1):265-275.

20. Irfan M, Shakoor A, Ali B, Elahi A, Tahira, Ghouri MI, et al. Structural and dielectric properties of polyaniline $/ \mathrm{TiO}_{2}$ Nanocomposites. European Academic Research. 2014;2(8):10602-10621.

21. Vishnuvardhan TK, Kulkarni VR, Basavaraja C, Raghavendra SC. Synthesis, characterization and a.c. conductivity of polypyrrole $/ \mathrm{Y}_{2} \mathrm{O}_{3}$ composites. Bulletin of Materials Science. 2006;29(1):77-83.

22. Sivakumar V, Suresh R, Giribabu K, Narayanan V. AgVO nanorods: Synthesis, characterization and visible light photocatalytic activity. Solid State Sciences. 2015;39:34-39. 